\title{
Review of the 2015 Guidelines for Maternity Care with relevance to congenital disorders
}

\author{
H L Malherbe, ${ }^{1}$ MSc; D L Woods, ${ }^{2}$ FRCP; C Aldous, ${ }^{1} \mathrm{PhD}$; A L Christianson, ${ }^{3}$ FRCP \\ ${ }^{1}$ School of Clinical Medicine, College of Health Sciences, University of KwaZulu-Natal, Durban, South Africa \\ ${ }^{2}$ School of Child and Adolescent Health, University of Cape Town, South Africa \\ ${ }^{3}$ Wits Centre for Ethics (WiCE), University of the Witwatersrand, Johannesburg, South Africa
}

Corresponding author: H L Malherbe (helen@hmconsult.co.za)

\begin{abstract}
The 4th edition of the Guidelines for Maternal Care in South Africa published by the National Department of Health in 2015 was evaluated with relevance to the care and prevention of congenital disorders (CDs). Disparate terminology is used for CDs throughout the guidelines, and overall less detail is included on CDs compared with the previous edition. This demonstrates a lack of awareness around the growing health need and contribution of CDs to the disease burden in South Africa (SA). Referrals to medical genetic services in the guidelines for mothers of advanced maternal age and other high-risk categories do not take into account the insufficient capacity available for screening and diagnosis of CDs. This highlights the lack of consultation with the medical genetics sector during the development of the guidelines. To respond to the Sustainable Development Goals by 2030, CDs must be integrated comprehensively at all levels of healthcare in SA.
\end{abstract}

S Afr Med J 2016;106(7):669-671. DOI:10.7196/SAMJ.2016.v106i7.10813

In 2015, the 4th edition of the Guidelines for Maternity Care in South Africa was published by the National Department of Health $(\mathrm{NDoH}) .^{[1]}$ A manual for clinics, community health centres and district hospitals, these replaced the previous 2007 edition. ${ }^{[2]}$

The guidelines provide, among other things, a practical approach for primary healthcare to manage pregnancy, labour and delivery in South Africa (SA) with the ultimate aim of reducing maternal mortality (deaths during pregnancy or within 42 days of delivery). With the maternal mortality ratio (MMR) estimated as having quadrupled in SA due to the HIV/AIDS epidemic, the need for such guidelines is clear. ${ }^{[3]}$ At 154 maternal deaths per 100000 live births in 2011 - 2013, the MMR was reduced to almost pre-HIV epidemic levels, but the Millennium Development Goal target of 38/100 000 live births was not achieved. ${ }^{[4,5]}$ Sights are now set on the Sustainable Development Goal of a global MMR of less than 70/100 000 by 2030. ${ }^{[6]}$

Owing to the inextricable link between mother and child, poor maternal health and maternal death are more likely to lead to death of the newborn. ${ }^{[7]}$ With $40 \%$ of under- 5 deaths occurring during the neonatal period in SA, and $75 \%$ of these occurring as early neonatal deaths, the benefits of quality prenatal care for the child are obvious. ${ }^{[8]}$ In $\mathrm{SA}$, deaths in infants and children under-5 decreased rapidly between 2008 and 2011, with a more modest improvement in neonatal deaths from 2009 to 2011, after which all these rates stagnated. ${ }^{[9]}$ Efforts to combat communicable diseases - including HIV/AIDS - continue, and interventions are underway such as those identified in the report by Chola et al. ${ }^{[10]}$ the childhood Expanded Program of Immunization, and improving social determinants of health; these will contribute to further reducing childhood deaths. However, for significant further reductions in childhood mortality and morbidity, including neonatal deaths, the contribution of congenital disorders (CDs) must be addressed. ${ }^{[11,12]}$

\section{The growing burden of congenital disorders}

Data from the Perinatal Problem Identification Program (PPIP) in 2014 indicated that congenital abnormalities have overtaken infection as the third leading cause of early neonatal deaths, after hypoxia and immaturity. ${ }^{[12,13]}$ Since congenital abnormalities (obvious structural CDs identified at birth) are a sub-group of CDs, the true death toll from CDs is likely to be much higher. CDs, which are abnormalities of structure or function present from birth - although they may only manifest later in life ${ }^{[14]}$ - are estimated to affect one in 15 live births in SA. ${ }^{[11]}$ CDs have not been prioritised as a healthcare issue in SA, despite World Health Assembly Resolution 63.17 of 2010 recognising their contribution to neonatal deaths and calling member states to action. ${ }^{[1,15]}$ The lack of accurate, empirical data has led to an underestimate of the true contribution of CDs to the burden of disease. ${ }^{[16,17]}$

The purpose of this article is to evaluate the 2015 Guidelines on Maternity Care with relevance to the care and prevention of CDs. ${ }^{[1]}$ Where appropriate, these will be compared with the previous edition of the guidelines within the current epidemiological context in SA..$^{[1,2]}$

\section{What is the aim of the Guidelines for Maternity Care?}

Prepared by the National Maternity Guidelines Committee at the $\mathrm{NDoH}$, the guidelines are for health workers (doctors and midwives) providing obstetric, surgical and anaesthetic services for pregnant women in primary healthcare facilities where specialist care is not normally available. ${ }^{[1]}$ Clinics, community health centres and district hospitals are encouraged to use the guidelines to develop protocols tailored to their specific needs, for identifying, diagnosing and managing common and serious pregnancy and delivery problems. Both editions of the guidelines respond to report recommendations by the National Committee on the Confidential Enquiry into Maternal Deaths, with the overall aim to improve clinical management and referral to reduce pregnancy-related deaths and ill health. ${ }^{[5]}$

While the 2015 guidelines follow a similar format to that of the previous edition, they also include some new chapters and omit others. $^{[1,2]}$ Content of relevance to CDs is included in chapters 2: Levels of care; 4: Antenatal care; 9: Problems in pregnancy; 10: Management of intra-uterine deaths, stillborn babies and neonatal 
deaths; and 15: Basic ultrasound at district level and routine postnatal care. Additional chapters in the 2015 edition do not include new content relevant to CDs; rather, the level of detail and quality of information on CDs has been decreased.

\section{Confusion in terminology}

The most notable difference in the 2015 edition is the use of 14 different terms to refer to CDs, whereas the 2007 edition consistently used the term 'birth defects and genetic disorders. ${ }^{[2]}$ The internationally agreed term 'congenital disorders' itself is not used in the document, although the synonym 'birth defects' is used several times. ${ }^{[14]}$ Unsupported by a glossary, the terms used include: congenital anomalies; congenital abnormality; congenital infection; chromosomal and congenital defect; abnormalities; structural and chromosomal fetal anomalies; birth defect; genetic or chromosomal defects; genetic disorder; genetic anomalies; genetic disease; familial and genetic disorder; fetal abnormalities; and fetal anomaly. Except for birth defects, these all refer to sub-sets of CDs, and some categories of CDs are excluded (personal communication, Bernadette Modell, November 2015). ${ }^{[14]}$ This inconsistent use of disparate terms for CDs is of concern and causes confusion around this healthcare issue.

\section{Teratogens}

In the 2015 edition, teratogens including alcohol, recreational drug use, maternal infections (rubella and syphilis), and the use of teratogenic medications during pregnancy are listed under 'risks for genetic disease. The risks associated with poorly controlled medical conditions are also listed, but diabetes mellitus is addressed elsewhere in the guidelines and hypothyroidism and iodine deficiency are not mentioned. With teratogens accounting for almost $20 \%$ of CDs in SA and affecting 14000 births annually, these need to be contextualised correctly, with greater emphasis placed on these preventable CDs. ${ }^{[11]}$

\section{Surveillance}

An exclusion from the 2015 guidelines is the regular compilation of data on the number of babies born with genetic disorders and major birth defects, as specified in the 2007 edition. In contrast, the 2015 edition refers only to the recording of mortalities, and recommends the PPIP format for data collation. This sole focus on deaths omits morbidity and the opportunity to provide vital data into national surveillance of CDs.

\section{Other content relevant to CDs}

The majority of content relevant to CDs is included in chapters 4: Antenatal care and 10: Management of intra-uterine deaths, stillborn babies and neonatal deaths. In chapter 4 , the importance of history taking for familial and genetic disorders to assess risk factors at the first antenatal visit is emphasised, as is $5 \mathrm{mg}$ of folic acid daily 3 months prior to and throughout pregnancy for the prevention of neural tube defects. A concise section entitled 'Risk of genetic disease' lists categories of women of childbearing age potentially at risk of having a child with a 'birth defect or genetic disorder', but includes non-genetic CDs. It recommends the provision of essential information to all pregnant women on specific topics including the avoidance of alcohol, tobacco and recreational drugs, the use of medication (self-care) and genetic disorders and birth defects relevant to newborn and infant care.

\section{Capacity constraints in} medical genetic services In chapter 10: Management of intra-uterine deaths, stillborn babies and neonatal deaths, genetic counselling and relevant referral should be provided as part of postpartum care when CDs are suspected, prior to another pregnancy in case of reoccurrence. Steps outlined to obtain a diagnosis when a CD is suspected as the cause of death include undertaking a history and a basic external examination. When a diagnosis cannot be made, a postmortem or whole body X-ray/ digital photography for referral to a geneticist is recommended. This does not take into account the limited capacity available in SA due to there being only 12 practising medical geneticists, clustered around academic centres in urban areas (Table 1). ${ }^{[12]}$

Capacity in the medical genetic services sector is further underestimated in chapter 15: Basic ultrasound at the district level. While acknowledging that routine screening for structural and fetal anomalies is 'not yet practical in the public sector', all women of advanced maternal age (specified as over 37 years) are referred to a specialist health facility or a maternal fetal ultrasound unit. This includes referral to a genetics clinic where consenting women should be routinely offered a scan, genetic counselling and invasive testing to rule out Down syndrome. It does not specify that genetic counselling should be undertaken prior to the scan and repeated afterwards in the case of abnormal findings. Women with a previous history or family history of structural, chromosomal or genetic disorders are also referred to specialist hospitals for structural screening and management decision. Analysis of recorded live births in 2013 indicates that 84260 births (8.5\%) were to women over 37 years. ${ }^{[22]}$ As outlined in Table 1, current capacity falls far short of recommended levels, with only 12 practising medical geneticists, fewer than 9 genetic counsellors and compromised laboratory services operating almost entirely from academic medical genetic departments countrywide. This available capacity makes it impossible for this number of referrals of women of advanced maternal age to be implemented. Medical genetic services relating to the care and prevention of $\mathrm{CDs}$ are in a state of decline and at a lower base today than prior to the HIV/AIDS epidemic. ${ }^{[1,12]}$

\section{Genetic couns elling}

In addition to referring high-risk women to regional and tertiary hospitals, genetic screening and counselling services are specified as a function of district hospitals in chapter 2: Levels of care. A significant contribution to the care of newborns is undertaken by nurses in these low-resourced primary healthcare settings, particularly in rural areas. These nurses, and general medical officers, are in the main not equipped with genetic counselling skills, and the nurses who are trained are in short supply. SA is also experiencing a severe shortage of doctors, with only 60 per 100000

Table 1. A comparison of medical genetics services capacity in 2001 and $2015^{[12]}$

\begin{tabular}{|c|c|c|c|c|c|}
\hline & Recommended (2003) ${ }^{[18]}$ & & 2001 & & 2015 \\
\hline Category & $\begin{array}{l}n \text { (ratio) } \\
(N=46.13 m)^{[19]}\end{array}$ & $n^{[20]}$ & $\begin{array}{l}\text { Ratio } \\
(N=44.82 \mathrm{~m})^{[19]}\end{array}$ & $n$ & $\begin{array}{l}\text { Ratio } \\
(N=54.96 \mathrm{~m})^{[21]}\end{array}$ \\
\hline Medical geneticists & $20(1$ per $2 \mathrm{~m})$ & 4 & 1 per $11.2 \mathrm{~m}$ & $12^{*}$ & 1 per $4.6 \mathrm{~m}$ \\
\hline Genetic counsellors & $80(1$ per 580000$)$ & $<20$ & 1 per $2.2 \mathrm{~m}$ & $9^{+}$ & 1 per $6.1 \mathrm{~m}$ \\
\hline $\begin{array}{l}\text { Medical scientists/ } \\
\text { technologists }\end{array}$ & $100(1$ per 450000$)$ & 50 & 1 per 900000 & $26^{\ddagger}$ & 1 per $2.1 \mathrm{~m}$ \\
\hline
\end{tabular}


population in 2013 compared with the global average of 152/100 000, and even fewer specialists (including medical geneticists). ${ }^{[23]}$ This places a huge strain upon the system and medical practitioners are overworked and often unsupported. This general lack of capacity of healthcare professionals at all levels must be rectified before such an under-resourced system can respond to additional demands.

\section{Conclusion}

As management guidelines, the 2015 edition responds to the policy directive to reduce maternal mortality by offering principles from which detailed institutional protocols can be developed. However, the guidelines are not cognisant of the limited infrastructure, capacity and resources available in the medical genetic services sector. The lack of investment in medical genetic services, largely due to competing health priorities, make it impossible for referrals in the guidelines to be implemented.

Consultation with the medical genetics community during the development of the 2015 edition could have prevented this disjoint and would have benefited from the ongoing review of the 2001 Policy Guidelines for the Management and Prevention of Genetic Disorders, Birth Defects and Disabilities. ${ }^{[20]}$

With SA once again in positive epidemiological transition, the proportion of neonatal, infant and child deaths from CDs will continue to increase as the country develops and communicable diseases are better controlled. ${ }^{[11,12]}$ Relevant, accessible and effective medical genetic services can prevent, cure and ameliorate CDs by up to $70 \%$ and may be the only way to significantly reduce child mortality further. ${ }^{[1,12,16,17,24]}$ If $\mathrm{SA}$ is to respond to Sustainable Development Goal 3 to end preventable deaths in newborns and reduce premature mortality from non-communicable diseases by two-thirds by 2030, CDs must be addressed comprehensively and funding allocated to build capacity and infrastructure in the sector. ${ }^{[6,12]}$ This response must permeate every level of implementation, to ensure no child is left behind.

Acknowledgements. Thanks to Prof. Eckhart Buchmann, National Maternity Guidelines Committee, for his feedback on the article.

\footnotetext{
1. National Department of Health, South Africa. Guidelines for Maternity Care in South Africa. A Manual for Clinics, Community Health Centres and District Hospitals. 4th ed. Pretoria: NDoH, 2015:172. http:// www.health.gov.za/index.php/2014-03-17-09-09-38/policies-and-guidelines/category/230-2015p\# (accessed 15 June 2015).
}

2. National Department of Health, South Africa. Guidelines for Maternity Care in South Africa. A Manual for Clinics, Community Health Centres and District Hospitals. 3rd ed. Pretoria: NDoH, 2007:171.

3. Burton R. Maternal health: There is a cause for optimism. S Afr Med J. 2013;103(8):520-521. DOI:10.7196/SAMJ.7237

4. United Nations. United Nations General Assembly, Resolution 55/2. United Nations Millennium Declaration, A/RES/55/2 18 September 2000. http://www.un.org/millennium/declaration/ares552e. html (accessed 13 January 2016).

5. National Committee for Confidential Enquiry into Maternal Death. Saving Mothers 2011 - 2013: Sixth 5. National Committee for Confidential Enquiry into Maternal Death. Saving Mothers 2011 - 2013: Sixth
Report on the Confidential Enquiry into Maternal Deaths in South Africa. Short Report. Pretoria: $\mathrm{NDoH}, 2014: 79$

6. United Nations. Sustainable Development Goal 3: Ensure Healthy Lives and Promote Wellbeing for All and at All Ages. http://www.un.org/sustainabledevelopment/health/ (accessed 1 February 2016).

7. Sines E, Tinker A, Ruben J. The Maternal-Newborn-Child Health Continuum of Care: A Collective Effort to Save Lives. Washington DC: Save the Children and Population Reference Bureau, 2006. http:// www.prb.org/pdf06/snl-contofcare_eng.pdf (accessed 20 January 2016).

8. Lloyd LG, de Witt TW. Neonatal mortality in South Africa: How are we doing and can we do better? S Afr Med J 2013;103(8):518-519. DOI:10.7196/SAMJ.7200

9. Dorrington R, Bradshaw D, Laubscher, R, Nannan N. Rapid Mortality Surveillance Report 2014. Cape Town: South African Medical Research Council, 2015. http://www.mrc.ac.za/bod/ RapidMortalitySurveillanceReport2014.pdf (accessed 26 January 2016).

10. Chola L, Pillay Y, Barron P, Tugendhaft A, Kerber K, Hofman K. Cost and impact of scaling up interventions to save lives of mothers and children: Taking South Africa closer to MDGs 4 and 5. Glob Health Action 2015;8:27265. DOI:10.3402/gha.v8.27265

11. Malherbe HL, Christianson AL, Aldous C. Need for services for the care and prevention of congenital disorders in South Africa as the country's epidemiological transition evolves. S Afr Med I 2015;105(3):186-188. DOI:10.7196/SAMJ.9136

12. Malherbe H, Aldous C, Woods D, Christianson A. The contribution of congenital disorders to chil mortality in South Africa. In: Padarath A, King J, Mackie E, Casciola J, eds. South African Health Review 2016, Chapter 12. 19th ed. Durban: Health Systems Trust, 2016:137-152.

13. Pattison R, Rhoda N. Saving Babies 2012 - 2013: Ninth Report on perinatal care in South Africa. Pretoria: Tshepesa Press, 2014:35. http://www.ppip.co.za/wp-content/uploads/SavingBabies-2012-2013.pdf (accessed 1 October 2014).

14. World Health Organization, March of Dimes. Management of Birth Defects and Haemoglobin Disorders. Report of a Joint WHO-March of Dimes Meeting, Geneva, Switzerland, $17-19$ May 2006. Geneva: World Health Organization, 2006. http://www.who.int/genomics/publications/WHO2006. Geneva: World Health Organization, 2006 .

15. World Health Assembly. Resolution 63.17. Birth Defects, WHA63.17 (21 May 2010). http://apps.who int/gb/ebwha/pdf_files/WHA63/A63_R17-en.pdf (accessed 2 September 2014)

16. Christianson CL, Modell B. Medical genetics in developing countries. Annu Rev Genomics Hum 6. Christianson CL, Modell B. Medical genetics in developing countries.
Genet 2004;5:219-265. DOI:10.1146/annurev.genom.5.061903.175935

17. Christianson A, Howson CP, Modell B. March of Dimes: Global Report on Birth Defects, the Hidden Toll of Dying and Disabled Children. New York: March of Dimes Birth Defects Foundation, 2006:85.

18. National Department of Health, South Africa. Strategic Framework for the Modernisation of Tertiary Hospital Services. Discussion Document. Pretoria: NDoH, 2003:86.

19. Statistics South Africa. South African Statistics 2014. Pretoria: Statistics South Africa, 2014.

20. National Department of Health, South Africa. Policy Guidelines for the Management and Prevention of Genetic Disorders, Birth Defects and Disabilities. Pretoria: NDoH, 2001.

21. Statistics South Africa. Mid-year Population Estimates 2015. Pretoria: Statistics South Africa, 2015

22. Statistics South Africa. Recorded Live Births 2013 (dataset). Pretoria: Statistics South Africa, 2015.

23. Econex. Identifying the determinants of and solutions to the shortage of doctors in South Africa: Is there a role for the private sector in medical education? Hospital Association of South Africa 2015. http://econex.co.za/wp-content/uploads/2015/08/ECONEX_Doctor-shortages-and-training 2015. http://econex.co.za/wp-con
FINAL1.pdf (accessed 1 Feb 2016)

24. Czeizel AE, Intôdy Z, Modell B. What proportion of congenital abnormalities can be prevented? BM] 1993;306(6876):499-503.

Accepted 4 April 2016 